\title{
Adsorption bed configurations for adsorption cooling application
}

\author{
Sebastian Stefański ${ }^{*}$, Łukasz Mika ${ }^{1}$, Karol Sztekler ${ }^{1}$, Wojciech Kalawa ${ }^{1}$, Łukasz Lis ${ }^{1}$, and \\ Wojciech Nowak $^{1}$ \\ ${ }^{1}$ AGH University of Science and Technology, Faculty of Energy and Fuels, 30-059 Kraków, Poland
}

\begin{abstract}
Important parameters used for adsorption chillers, e.g. cooling capacity, coefficient of performance, are strictly dependent on heat and mass transfer conditions between adsorbent mass and the cooling/heating medium. With the aim of energy efficiency increasing it is essential to reduce heat transfer resistance. Different bed configurations and heat exchangers constructions are recommended for adsorption bed application. In the paper the review of commonly used adsorption bed configurations, i.e. loose-grain beds or fixed beds, is presented. Also, different heat exchangers for adsorption technology were described. The characteristic features of commonly applied constructions, both for commercial use and scientific research, were presented. The experimental studies presented in the literature were investigated and the substantial conclusions from the literature review are mentioned. Also, the proposition of new adsorption bed construction using the binder and additives was mentioned.
\end{abstract}

\section{Introduction}

According to a report released in 2018 by the International Energy Agency [1], air conditioning and cooling systems account for about $20 \%$ of buildings electricity demands and about $10 \%$ of global electricity demand. Factors like increasing thermal comfort expectations, affordable cooling technologies or rapidly growing global population, contribute to a systematic rise in energy needs for cooling. The IEA's projections indicate that in the absence of action in the field of the energy efficiency of cold production, the share of air conditioning installations in global electricity consumption may increase more than threefold by 2050 . Attention needs to be drawn to the fact of limited resources of solid fuels and the climate change issue. Increasing ambient temperature results in increased cooling demands while the method of cooling generation has significant impact on climate change through, e.g. excess heat release or greenhouse gas emission. The solution to abovementioned issue may be a considerable energy efficiency improvement of cold production or the implementation of alternative technology. However, it appears to be very difficult to find cooling technology with comparable energy efficiency (Coefficient of Performance - COP). Those problems can be partially solved with applying both absorption (ABS) and adsorption (ADS) chillers using a heat flux as an energy source.

\footnotetext{
* Corresponding author: stefanski@agh.edu.pl
} 
Currently available sorption chillers achieve lower value of COP than average compression cooling systems. Both $\mathrm{ABC}$ and $\mathrm{ADC}$ devices cannot fully replace compression technology because of working temperatures limited by evaporation conditions [2], e.g. chilled water temperature lower than $3-5^{\circ} \mathrm{C}$ is infeasible in ADC using water as a working fluid. Despite abovementioned disadvantages using sorption chillers can be economically founded due to low-temperature heat utilization against using electricity, which is most valuable form of energy. Absorption and adsorption devices can be driven by heat coming from combustion, but also from renewable energy sources, e.g. solar collectors or PV panels, and technological processes. Efficiency of system with cooling installation can be easily improved with $\mathrm{ADC}$ or $\mathrm{ABC}$. Creating such a hybrid system can be cost-effective if waste heat is available and cooling demands are important for the system.

\section{Adsorption chillers}

The choice between absorption and adsorption chillers can be made on the basis of available waste heat temperature, expected chilled water temperature and size or mass restrictions. Commonly ADC devices can be driven by lower temperature heat than $\mathrm{ABC}$ ones. The COP value of adsorption chillers is usually lower at the same hot water temperature but it can be compensated by the amount of low-temperature heat possible to utilize because minimum temperature $\mathrm{ADCs}$ need to work is $20-40^{\circ} \mathrm{C}$ lower than for $\mathrm{ABCs}$ [3]. The important advantage of adsorption technology is possibility of water desalination. For devices using water as a working fluid, e.g. silica gel-water working pair, water coming from the condenser is purified from dissolved salts and other minerals. Integrating with other desalination technology it is possible to produce freshwater in an effective way. Nowadays this feature is becoming more important, especially in regions having freshwater deficit. Such regions have also great solar energy potential and usually high cooling demands, e.g. Middle East region, Singapore.

Operating principle of ADC is based on physical adsorption phenomenon, that is adhesion of adsorbate molecules (working fluid) to the adsorbent (solid sorption material). To create cooling effect, three basic elements are needed, i.e. evaporator, adsorption bed and condenser. Under vacuum conditions the working fluid (e.g. water) evaporates in one or two stage evaporator. During evaporation process, the heat is received from medium circulating in external cooling circuit. In the next step working fluid vapor gets into adsorption bed, where adsorption process starts. The adsorption bed is placed in vacuum chamber and its construction is based on heat exchanger (HEX) filled with adsorbent. In the adsorbent both adsorption and desorption (regeneration) processes are carried out. Those processes are exothermic and endothermic respectively, and the heat is transferred between adsorbent and cooling and heating medium depending on process currently carried out. Adsorption and desorption processed are carried out alternatively in the adsorption bed that is cooling cycle is not continuous. During the exothermic adsorption process heat is released and the bed is cooled with external cooling medium with the temperature of approximately $20-40^{\circ} \mathrm{C}$. In order to enable carrying out the next cycle, the bed has to be regenerated during desorption process. In this case heat with the temperature of about $50-90^{\circ} \mathrm{C}$ is supplied to adsorption bed and working fluid vapor is released from adsorbent. Working fluid vapor are turned to liquid in the condenser. The cycle is closed by supplying condensate back to the evaporator or collected in desalinated water tank/installation.

Due to adsorption bed construction and sorption capacity of typical materials, adsorption chillers are characterized by higher weight than absorption equivalents that is specific cooling capacity (SCC) is lower. The SCC values are strongly influenced by hot medium temperature during desorption phase and external cooling circuit the heat is received from. In case of low SCC value the adsorbent mass have to be increased in order to achieve expected cooling 
capacity. It is significant to choose adsorbent material with the great sorption capacity and cheap enough to make the installation cost-effective.

The important issue analyzed in literature is heat transfer between adsorbent and cooling/heating medium. High porosity and granular form of adsorbent are one of the reason of high heat transfer resistance in adsorption bed. The second issue is thermal contact resistance between adsorbent layer and heat exchanger surface. Abovementioned features are responsible for adsorption and desorption rate limitation. In order to achieve cooling capacity resulting from sorption capacity of adsorbent, the homogeneous bed temperature distribution is significant. If unevenness in temperature distribution are observed, decrease of adsorbed vapor mass can occur. Due to the fact that it is not possible to avoid entirely temperature fluctuations, HEX with heat transfer surface area are applied and the amount of adsorbent may be more than compensate. Increasing heat transfer surface area with e.g. larger number of fins is limited because of decreasing space designed to fill with adsorbent what is crucial for cooling capacity.

Apart from heat transfer intensification it is significant to ensure access for adsorbate molecules to adsorbent grains, that is to avoid pressure drop growth. Sorption capacity of the bed can decrease rapidly if the pressure drop precludes adsorbate diffusion to some parts of adsorbent layer.

As it is demonstrated, the issue of improving HEX construction with keeping heat and mass transfer condition suitable is complex. Multi-objective analysis and experimental tests are necessary for the purpose of finding the appropriate bed. Different bed configurations and HEX constructions are presented in literature and most often applied were described in this review paper.

\section{Adsorption bed configurations}

There are few types of heat exchangers applied in commercial and prototype refrigerators. The entire adsorption beds can also differ markedly in terms of construction. The complexity of processes carried out in ADC impedes identifying an influence of bed construction on a chiller performance. The modification of adsorption bed may be noticeable in values of important parameters, e.g. COP and cooling capacity. Therefore, the comparison of two chillers with different bed construction cannot be based on one indicator. The most relevant parameters for analysis and comparison of different solutions are as follows [4]:

- CC (cooling capacity),

- COP (coefficient of performance),

- SCC (specific cooling capacity per kilogram adsorbent), $\mathrm{W} / \mathrm{kg}_{\text {ads }}$,

- SDWP (specific daily water production) - used in case of chillers with desalination function, $\mathrm{m}^{3} / \mathrm{kg}_{\text {ads }}$ per day,

- HCR (heat capacity ratio) - the ratio of the adsorbent heat capacity to metal heat capacity (the mass of metallic part of bed) [5], or the ratio of the mass of the metal part of the bed to the mass of adsorbent,

- half cycle time - the duration of the adsorption and preheating processes or the desorption and precooling processes; in case of different desorption and adsorption times, the cycle ratio parameter shall be,

- the temperature of hot medium used during regeneration, the temperature of cooling medium used during adsorption process, the temperature of chilled water (outlet water from the evaporator)

- the mass and volume of adsorbent packed in bed, a net weight of a heat exchanger,

- the adsorbent particle size,

- sorption capacity,

- vapor pressure drop in the adsorption bed. 
In 1848 Faraday observed that $\mathrm{AgCl}_{2}$ adsorbing $\mathrm{NH}_{3}$ can be followed with cooling effect generation [4]. In the 1920s the adsorption chiller using silica gel and $\mathrm{SO}_{2}$ were developed and applied in train to provide food storage conditions. The device was driven by heat from propane combustion and air-cooled [6]. Rapid progress in compression cooling technology resulted in fall in adsorption cooling development. Since 70s the interest in ADC has been rising and last 20 years brought great progress in adsorption cooling technology. Commercial compact devices are now available on the refrigeration market. Research are currently focused on bed modifications, operation controlling, adsorbents and hybrid systems including ADCs [4]. Using various heat exchangers combined with different adsorbent placement method result in several bed types, e.g. granular bed, coated bed, consolidated bed [4].

\subsection{Fin-tube heat exchanger}

Fin-tube heat exchangers are simple constructions based on straight tube with perpendicular fins. Finned tube can be used as single straight line (Fig. 1a) connected in parallel, shaped into coil with finned straight elements or u-tube with fins (Fig. 1b). Fins may have circular or rectangular shape.
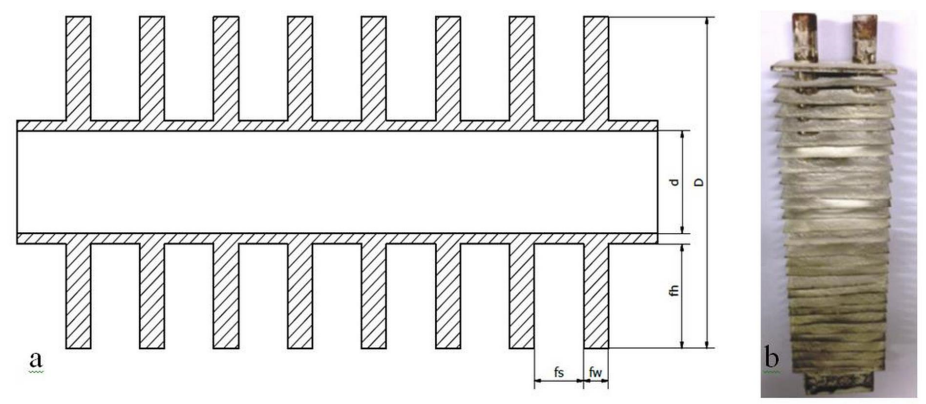

Fig. 1. Schematic diagram (a) and photograph (b) [7] of fin-tube heat exchanger. Characteristic dimensions: $\mathrm{D}$ - HEX diameter, $\mathrm{d}$ - tube diameter, $\mathrm{f}_{\mathrm{h}}-$ fin height, $\mathrm{f}_{\mathrm{w}}-$ fin width, $\mathrm{f}_{\mathrm{s}}-$ fin spacing.

Fin-tube HEX can be adapted do adsorption bed by filling space between fins with loose grains of adsorbent and covering with mesh in case of keeping adsorbent grains in place. Also it is possible to cover heat exchanger surface with coating made from adsorbent grains and binder. Poyelle et al. [8] tested granular and consolidated bed using zeolite and fit-tube HEX. Two-bed adsorption chiller with heat and mass recovery was used. It was found that SCC value can increase three-fold to $97 \mathrm{~W} \cdot \mathrm{kg}^{-1}$ and significant influence heat and mass transfer resistances in bed on both SCC and COP was noticed. Specific cooling capacity decrease while thermal conductivity in the bed lowers and COP value rise at lower vapor pressure drop in adsorbent layer. Similar observation were made by Restuccia et al. [9] during experiments on chiller with SWS-1L material as the adsorbent.

Fins applied in such type of HEX may have different geometry. The comprehensive analysis of typical geometric parameters (Fig. 1) influence on chiller performance was conducted [10,11]. Rectangular and circular fins were compared for various fin spacing $(3,6,9,12 \mathrm{~mm})$ and height $(15-70 \mathrm{~mm})$. Increasing fin height require supplying more heat for regeneration, but it was indicated that at the same time COP value rises. The cooling capacity increment exceeds higher heating demands. Due to analysis, using circular fins is recommended for the purpose of improving SCC value, especially when the cheap heat source is available.

Despite the fact that properties of consolidated and coated beds are often pointed out as more suitable, the promising results can be obtained also using loose grains of adsorbent. In 
the experimental tests [12] of bed with HEX filled in with adsorbent grains and covered with mesh, the COP achieved value of 0.54 and the SCC was $73 \mathrm{~W} / \mathrm{kg}_{\text {ads. The }}$ These values can be very promising, especially considering simplicity of bed construction.

Similar bed construction, dedicated to A/C system for automotive, was also analyzed by Sharafian A. et al. 2015 [13]. Rectangular plates were placed on u-tube and were substitution to convectional ribs. It was found that in case of using loose grains, the fin spacing is recommended to be double adsorbent grain size while length of the whole HEX remains unchanged. Research on using silica gel in coated bed design was performed by Li A. et al. $[7,14]$. Hydroxyethylcellulose (HEC) was selected from few different binders, e.g. epoxy resin, polyvinyl alcohol, bentonite. Adding binder to powdered silica gel enabled preparing solid layer with thickness of $0.7 \mathrm{~mm}$ on heat exchanger surface with no influence on sorption capacity. Examining the influence of the fin design parameters on chiller with thermal wave cycle operation in numerical simulation, Caglar [15] demonstrated that the fin thickness increase does not improve adsorbent temperature distribution. However, the fin height $f_{h}$ and fin spacing $f_{s}$ analysis indicated that fin height increase has a negative impact on heat transfer processes in adsorption bed. Lowering fin spacing has proved beneficial but it lowers adsorbent mass at the same time, so the cooling capacity also decreases.

\subsection{Plate fin-tube heat exchanger}

Another HEX type is based on finned tubes placed in parallel to each other creating a flat surface. The heat transfer surface is enlarged by plate fins placed in perpendicular to tubes. This solution is used extensively e.g. in air coolers and radiators; evaporators and condensers of HVAC devices and in vehicle radiators. A simple design of such heat exchanger type could serve as the basis for adsorption bed. Due to adapting this type HEX to adsorption bed is not complicated due to easy access to spaces between fins and tubes. There is also possibility to construct coated bed. The advantage of these solutions is the possibility to increase cooling capacity by constructing heat exchangers stack. In granular beds grains are kept in place by mesh. What is more, this solution enables working fluid vapor distribution throughout the whole cross-sections surface of bed. Solutions of this type are used in commercial chillers [16-19]. This exchanger may be presented in simplified terms shown in Figure 2. The studies $[20,5]$ used genetic algorithm for determining appropriate cycle time and fin spacing of HEX focusing on maximizing cooling capacity. It was demonstrated, that thermal contact resistance between HEX surface and adsorbent layer limits operating parameters of chiller. It was estimated to account for $25 \%$ of the total thermal resistance in bed. At the same time, a problem with mass transfer in beds using adsorbent with binder was identified. The proposed solution included solving the problem by glueing a thin layer of adsorbent and then filling free spaces with loose grains of adsorbent. The analysis was based on commercial silica gel-water chiller.

The combined solution with partially glued adsorbent may be easily applied. Possible technological problems with their production can be solved by increasing HEX fin spacing. It facilitates access to the HEX surface and do not affect working parameters significantlydoubling $\mathrm{f}_{\mathrm{s}}$ results in $17 \%$ decrease of cooling capacity [20].

It is therefore possible to reduce thermal contact resistance with powdered metal additives [5]. Expected improvement of adsorbent layer thermal conductivity are around 1.5-fold increase at 15 w.t. \% of copper or brass and even 2.4 -fold increase at 15 w.t. \% aluminum. According to [21], using grains bigger than those used in bed with loose grains is recommended for constructing coated beds. Coated bed was also analyzed in [22], in which a high value of $\mathrm{COP}-0.48$ - was achieved at hot water temperature.

Chen C.J. et al. [23] tested plate fin tube HEX with circular instead of rectangular fins. The circular fins filled all available spaces between tubes, but there were also free spaces left 
not covered with fins used for mass distribution. It also improved heat transfer in adsorbent layer as the silica gel layer was placed annularly.
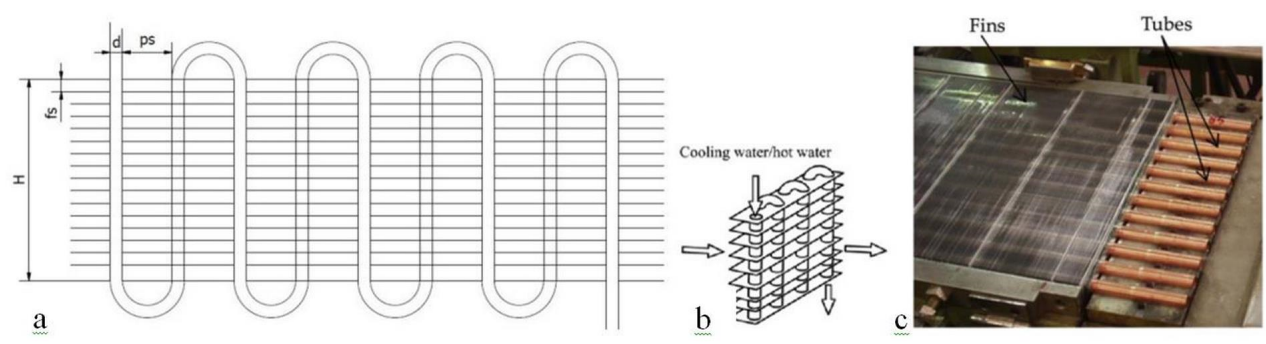

Fig. 2. Schematic diagram (a),(b) [22] and photograph (c) [20] of plate-fin-tube heat exchanger. Characteristic dimensions: $\mathrm{H}$ - HEX height, $\mathrm{d}$ - tube diameter, $\mathrm{ps}$ - pipe spacing, $\mathrm{fs}$ - fin spacing.

\subsection{Finned flat-tube heat exchanger}

The different version of plate fin tube HEX uses flat tubes with corrugated fins instead of conventional construction described in subsection 3.2 may be applied in ADCs [24-28]. Such type HEX are used in automotive industry, e.g. as the evaporators for air conditioning [24]. The schematic diagram is presented in Figure 3.
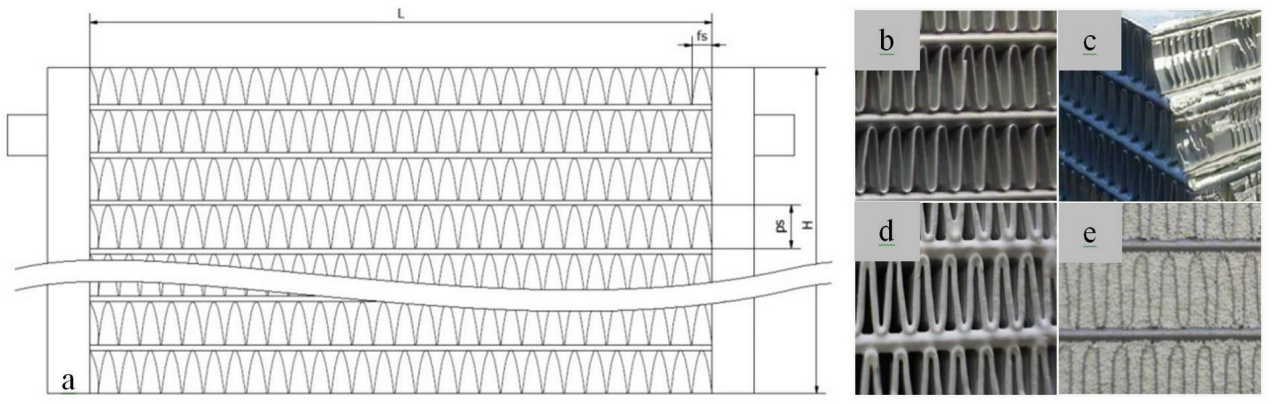

Fig. 3. Schematic diagram (a) and photographs [27] of flat-tube heat exchanger: b,c - blank HEX, dcoated bed, $\mathrm{e}-$ granular bed. Characteristic dimensions: $\mathrm{H}-\mathrm{HEX}$ height, $\mathrm{L}-\mathrm{HEX}$ length, $\mathrm{p}_{\mathrm{s}}-$ pipe spacing, $\mathrm{fs}_{\mathrm{s}}-$ fin spacing.

Freni et al. [27] examined the possibility to construct granular and coated beds with SAPO-34 using described HEX type. Using coated bed with silane-based binder of a thickness of $0.1 \mathrm{~mm}$ provided COP of 0.24 while for granular bed COP was 0.4 . It should be noted that in case of coated bed the adsorbent mass was 3 times lower. The proposed coating type enabled significant increase of SCC - from 500 to $675 \mathrm{~W} / \mathrm{kg}$. Coated bed demonstrated a higher sorption capacity. The same heat exchanger was examined in [29] in several systems differing in proportion of height $\mathrm{H}$ to length $\mathrm{L}$ and position of HEX elements in the stack. It was demonstrated that keeping a simple design of granular bed, it is possible to achieve high values of operating parameters - experimentally estimated SCC was $2.3 \mathrm{~kW} / \mathrm{kgads}$. As it was presented in other papers (e.g. [24]), using grains of size of 0.3-0.6 mm was recommended due to mass transfer conditions and adsorption/desorption rate.

The influence of flat-tube HEX geometry was analyzed by Rogala with model [30] by determining the fin height and fin spacing ranges for which chiller performance is the highest. The numerical analysis [30] showed that finding appropriate HEX geometric parameters and grains size have significant influence in heat transfer surface area and heat transfer rate. At the same time the proposed construction may be produced without serious technological 
problems. The COP and the SCC increase of respectively, 3.7\% and $6.3 \%$ was estimated while silica gel grains was of diameter of $0.3 \mathrm{~mm}$.

\subsection{Other constructions}

Besides using generally available heat exchangers for designing adsorption bed, there are also recommended constructions which are dedicated for this purpose. U-tube-based solution was proposed by S. Mitra et al. [31]. Adsorption bed of that type have a simple construction, what makes filling the adsorption bed with adsorbent easy. However, COP and SCP values differed from the values reached by the chillers with a different constructions. Modular constructions are increasingly popular. The solution which include alternating layers of silica gel channel, water channel and mass transfer channel was proposed by Liu et al. [32,33]. The COP value in the range of 0.33 to 0.42 at hot water temperature of $70^{\circ} \mathrm{C}$ was obtained while a simple bed construction was applied.

Modular constructions were also presented in the papers [34,35], in which the authors' proposal was examined in numerical analysis. The first proposal included rectangular modules of silica gel placed between cooling and hot water channels while working fluid vapor distribution was implemented by additional space separating the modules (Fig. 4a). Compared to solutions used commercially, a higher value of cooling capacity to adsorber volume ratio was achieved. The use of working fluid vapor channel is necessary for efficient adsorption bed operation. Placing the silica gel modules in grooved plates was proposed for the second construction (Fig. 4b). It included cooling/hot water channels hollowed in the plate located/placed below adsorbent modules. The distribution of water vapor was implemented by additional channels and by contact with the largest wall of cuboidal silica gel module.

Modular constructions enable easy device extension to an expected cooling capacity. Through dividing adsorber into smaller elements they may improve cooling capacity to adsorber volume ratio what makes the whole device smaller. Such solutions, unlike those using conventional heat exchangers, require extensive analyses and developing a new technology of mentioned heat exchangers production.
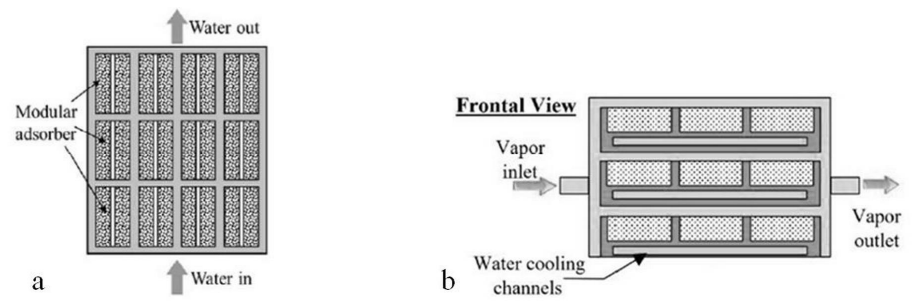

Fig. 4. Schematic diagrams of modular adsorbent beds by R.H. Mohammed et al. [34] (a), [35] (b).

\section{Author's research}

Adsorption bed modifications focus on heat transfer intensification in bed and its influence on working parameters. Many research studies indicated both granular and coated beds' advantages. In the table 1. some literature results are presented and compared.

Lowering the thermal contact resistance improve the device's performance, but filling space between adsorbent grains with binder or powdered adsorbent influences permeability of adsorbent layer. For this reason coating layer thickness higher than few millimeters is not recommended due to increasing adsorption/desorption time in relation to thinner coatings [36]. For thinner coating adsorbent mass decreases lowering cooling capacity. The solution 
Table 1. The comparison of operation parameters of different adsorption bed configurations.

\begin{tabular}{|c|c|c|c|c|c|c|c|c|c|c|c|c|c|c|}
\hline & $\begin{array}{c}\text { Ref. } \\
\text { no. }\end{array}$ & Year & $\begin{array}{l}\text { Adsorbent- } \\
\text { adsorbate }\end{array}$ & $\left|\begin{array}{c}\text { Adsorbent bed } \\
\text { type }\end{array}\right|$ & Grain size & COP & $\begin{array}{l}\text { SCC } \\
(\mathrm{W} / \mathrm{kg})\end{array}$ & $\begin{array}{l}\text { Hot water }(\mathrm{HW}) / \\
\text { desorption temp. }\end{array}$ & $\begin{array}{l}\text { Chilled water } \\
\text { (ChW) temp. }\end{array}$ & \begin{tabular}{|c|} 
Cooling water \\
$(\mathrm{CW}) /$ \\
adsorption temp.
\end{tabular} & Cycle time & $\begin{array}{l}\text { Characteristic dimensions } \\
\text { od HEX }\end{array}$ & \begin{tabular}{|c|} 
Metal to \\
adsorbent \\
mass ratio
\end{tabular} & Remarks \\
\hline \multirow{4}{*}{ 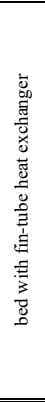 } & 8 & 1999 & $\begin{array}{c}\text { natural expanded } \\
\text { graphite and } \\
\text { zeolite - water }\end{array}$ & consolidated & - & 0.41 & 97 & $230^{\circ} \mathrm{C}$ & $4^{\circ} \mathrm{C}$ & $40^{\circ} \mathrm{C}$ & $60 \mathrm{~min}$ & - & - & $\begin{array}{l}\text { Experimental study. Changing the cycle time indicated } \\
\text { influence of water vapour flow resistance on chiller operation } \\
\text { parameters. After shortening the time cycle from } 60 \text { to } 20 \text { min } \\
\text { the COP decreased from } 0.41 \text { to } 0.28 \text { without any change in } \\
\text { SCC value. }\end{array}$ \\
\hline & 9 & 2004 & SWS-1L - water & $\begin{array}{c}\text { loose grains / } \\
\text { pelletised }\end{array}$ & $0.8-1.6$ & $0.55-0.60 \mid$ & 20 & $85-95^{\circ} \mathrm{C}$ & $10^{\circ} \mathrm{C}$ & $\begin{array}{l}\text { Minimum bed } \\
\text { temp. } 35-40^{\circ} \mathrm{C}\end{array}$ & $160 \mathrm{~min}$ & \begin{tabular}{|l} 
Fin spacing $\mathrm{fs}=7 \mathrm{~mm}$ \\
Fin width $\mathrm{fw}=0.4 \mathrm{~mm}$
\end{tabular} & 3 & $\begin{array}{l}\text { Experimental study and modelling. Composite sorbents enable } \\
\text { reaching COP of } 0.6 \text {, and low value of SCC can be increased by } \\
\text { using consolidated or coated type of adsorption bed. } \\
\end{array}$ \\
\hline & 37 & 2007 & SWS-1L - water & $\begin{array}{c}\text { coated } \\
\text { (with } \\
\text { bentonite) }\end{array}$ & - & $0.15-0.3$ & $150-200$ & $90-100^{\circ} \mathrm{C}$ & $7-12^{\circ} \mathrm{C}$ & $25-35^{\circ} \mathrm{C}$ & $\sim 10 \mathrm{~min}$ & Tube diameter $\mathrm{d}=16 \mathrm{~mm}$ & $\sim 3.4$ & $\begin{array}{l}\text { Experimental study. After } 100 \text { cycles mechanical and sorption } \\
\text { properties have not changed. The COP value reached in this } \\
\text { stsudy was lower than pelletised bed presented by Restuccia et } \\
\text { al., probably due to shorter cycle time. }\end{array}$ \\
\hline & 12 & 2014 & silica gel - water & loose grains & $0.5 \mathrm{~mm}$ & $\sim 0.42$ & $\sim 87$ & $77.5^{\circ} \mathrm{C}$ & $12^{\circ} \mathrm{C}$ & $25^{\circ} \mathrm{C}$ & $\sim 17 \min *$ & $\begin{array}{l}\text { Tube diameter } \mathrm{d}=5 \mathrm{~mm} \\
\text { Fin height } \mathrm{fh}=14.8 \mathrm{~mm} \\
\text { Fin width fi }=1 \mathrm{~mm} \\
\text { Fin spacing fs }=1 \mathrm{~mm}\end{array}$ & - & $\begin{array}{l}\text { Experimental study. Maximum COP was } 0.54 \text { for cycle time of } \\
35 \text { min. while SCC reached } 73 \mathrm{~W} / \mathrm{kg} \text {. Fin spacing of } 4 \mathrm{~mm} \\
\text { occurred to be too large what prevented dynamic bed } \\
\text { regeneration. }\end{array}$ \\
\hline \multirow{4}{*}{ 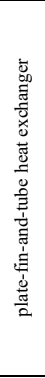 } & 23 & 2010 & silica gel - water & loose grains & $\begin{array}{c}0.5-1.5 \\
\mathrm{~mm}\end{array}$ & 0.49 & - & $\begin{array}{l}\mathrm{HW} \text { inlet temp. } \\
82.1^{\circ} \mathrm{C}\end{array}$ & \begin{tabular}{|c|}
$\mathrm{ChW}$ inlet/outlet \\
temp. \\
$18.9 / 12.3^{\circ} \mathrm{C}$ \\
\end{tabular} & $\begin{array}{l}\mathrm{CW} \text { inlet temp. } \\
31.6^{\circ} \mathrm{C}\end{array}$ & - & Fin spacing $\mathrm{fs}=2.5 \mathrm{~mm}$ & - & $\begin{array}{l}\text { Experimental study. The device without vacuum valves. The } \\
\text { plate heat exhchanger with u-tubes and annular fins applied and } \\
\text { filled with granular silica gel. }\end{array}$ \\
\hline & 17 & 2015 & silica gel - water & loose grains & - & 0.642 & - & $56.5^{\circ} \mathrm{C}$ & $5-12^{\circ} \mathrm{C}$ & $25^{\circ} \mathrm{C}$ & - & - & - & $\begin{array}{l}\text { Experimental study. Maximum cooling capacity of } 90.5 \mathrm{~kW} \\
\text { was reached at following conditions: heating water temperature } \\
\text { of } \quad 64^{\circ} \mathrm{C} \text { cooling water temperature of of } \\
25^{\circ} \mathrm{C} \text {. Decreasing cooling water temperature to } 20^{\circ} \mathrm{C} \text { enabled to } \\
\text { increase cooling capacity to } 119 \mathrm{~kW} \text {. }\end{array}$ \\
\hline & 36 & 2009 & silica gel - water & $\begin{array}{c}\text { coated } \\
\text { (with PVAc) }\end{array}$ & $\begin{array}{c}0.5-1.5 \\
\mathrm{~mm}\end{array}$ & 0.37 & 72 & $\begin{array}{l}\mathrm{HW} \text { inlet temp. } \\
80^{\circ} \mathrm{C}\end{array}$ & $\begin{array}{l}\text { ChW inlet temp. } \\
30^{\circ} \mathrm{C}\end{array}$ & $\begin{array}{l}\mathrm{CW} \text { inlet temp. } \\
14^{\circ} \mathrm{C} \\
\end{array}$ & $12.4 \mathrm{~min}$ & - & - & $\begin{array}{l}\text { Experimental study. The system was powered from solar } \\
\text { collectors. The PVAc was used as a binder. }\end{array}$ \\
\hline & 38 & 2011 & silica gel - water & loose grains & & 0.44 & & $\underset{\sim 82-90^{\circ} \mathrm{C}}{\mathrm{HW} \text { outlet }}$ & $15^{\circ} \mathrm{C}$ & $\underset{\sim 35-42^{\circ} \mathrm{C}}{\mathrm{CW}}$ & $6 \mathrm{~min}$ & - & 1 & $\begin{array}{l}\text { Experimental study and modelling. The two-bed chiller was } \\
\text { constructed on the basis of commercial heat exchanger designed } \\
\text { for automotive industry. Three heat exchangers was placed } \\
\text { together in parallel configuration. COP value without using heat } \\
\text { recovery system was } 0.29 \text {. }\end{array}$ \\
\hline \multirow{4}{*}{ 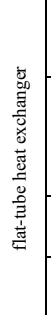 } & 24 & 2005 & silica gel - water & loose grains & $\begin{array}{c}0.2-1.0 \\
\mathrm{~mm}\end{array}$ & - & 300 & $\begin{array}{l}\mathrm{HW} \text { inlet temp. } \\
65-80^{\circ} \mathrm{C}\end{array}$ & - & $\underset{\sim}{\text { Adsorbent temp. }} \underset{\sim 20^{\circ} \mathrm{C}}{ }$ & $10 \mathrm{~min}$ & - & $\sim 2$ & $\begin{array}{l}\text { Experimental study. Using silica gel grains with size of } \\
0.7-1.5 \mathrm{~mm} \text { resulted in lower cooling capacity - lower mass of } \\
\text { silica gel was packed in the heat exchanger. }\end{array}$ \\
\hline & 25 & 2007 & silica gel - water & $\begin{array}{l}\text { consolidated } \\
\text { (with PVAc) }\end{array}$ & $\begin{array}{c}0.5-1.5 \\
\mathrm{~mm}\end{array}$ & 0.45 & 176 & $\begin{array}{l}\mathrm{HW} \text { inlet temp. } \\
80^{\circ} \mathrm{C}\end{array}$ & $\begin{array}{l}\mathrm{ChW} \text { inlet temp. } \\
25^{\circ} \mathrm{C}\end{array}$ & $\begin{array}{l}\mathrm{CW} \text { inlet temp. } \\
114^{\circ} \mathrm{C}\end{array}$ & $6 \mathrm{~min}$ & $\begin{array}{l}\text { Length } L=668 \mathrm{~mm} \\
\text { Height } \mathrm{H}=330.2 \mathrm{~mm} \\
\text { Fin spacing } \mathrm{fs}=\sim 1.8 \mathrm{~mm}\end{array}$ & - & $\begin{array}{l}\text { Experimental study. The adsorption bed was composed of } 15 \\
\text { heat exchanger and } 24.5 \mathrm{~kg} \text { of silica gel packed together with a } \\
\text { binder. Maximum COP value was } 0.53 \text { while chilled water } \\
\text { temperature was set on } 20^{\circ} \mathrm{C} \text { and hot water flow rate was } \\
\text { decreased. }\end{array}$ \\
\hline & 27 & 2015 & SAPO-34 - water & granular & $\begin{array}{c}0.6-0.7 \\
\mathrm{~mm}\end{array}$ & 0.4 & 498 & $\begin{array}{l}\mathrm{HW} \text { inlet temp. } \\
\quad 90^{\circ} \mathrm{C}\end{array}$ & $\begin{array}{l}\mathrm{ChW} \text { inlet temp. } \\
28^{\circ} \mathrm{C}\end{array}$ & $\begin{array}{l}\mathrm{CW} \text { inlet temp. } \\
15^{\circ} \mathrm{C}\end{array}$ & $5 \min$ & $\begin{array}{l}\text { Length } \mathrm{L}=235 \mathrm{~mm} \\
\text { Height } \mathrm{H}=157 \mathrm{~mm}\end{array}$ & 1.96 & \multirow{2}{*}{$\begin{array}{l}\text { Experimental study. The prototype chiller with cooling capacity } \\
\text { od } 1 \mathrm{~kW} \text {; mechanical properties have not changed during } 600 \\
\text { cycle test. }\end{array}$} \\
\hline & 27 & 2015 & SAPO-34 - water & $\begin{array}{c}\text { coated (silane- } \\
\text { based binder) }\end{array}$ & - & 0.24 & 675 & $\begin{array}{l}\mathrm{HW} \text { inlet temp. } \\
90^{\circ} \mathrm{C}\end{array}$ & $\begin{array}{l}\text { ChW inlet temp. } \\
\qquad 28^{\circ} \mathrm{C}\end{array}$ & $\begin{array}{l}\mathrm{CW} \text { inlet temp. } \\
15^{\circ} \mathrm{C}\end{array}$ & $5 \min$ & $\begin{array}{l}\text { Length } \mathrm{L}=235 \mathrm{~mm} \\
\text { Height } \mathrm{H}=157 \mathrm{~mm}\end{array}$ & 6 & \\
\hline
\end{tabular}


of this problem may be finding the way to increase heat transfer coefficient of the layer with no permeability drop.

The possibility of preparing coated bed with silica gel grains smaller than $300 \mu \mathrm{m}$ and from the range of 710 to $1000 \mu \mathrm{m}$ packed together with an organic binder was tested. The influence of additives, e.g. aluminum powder on physical properties was studied. It was found that using binder and $<20 \mathrm{wt} \%$ metal powders enables preparing coating resistant to mechanical stresses occurring in adsorption bed. The influence of used additives on thermal conductivity have to be examined and tested in prototype scale. The photographs of four selected samples are presented in Fig. 5.

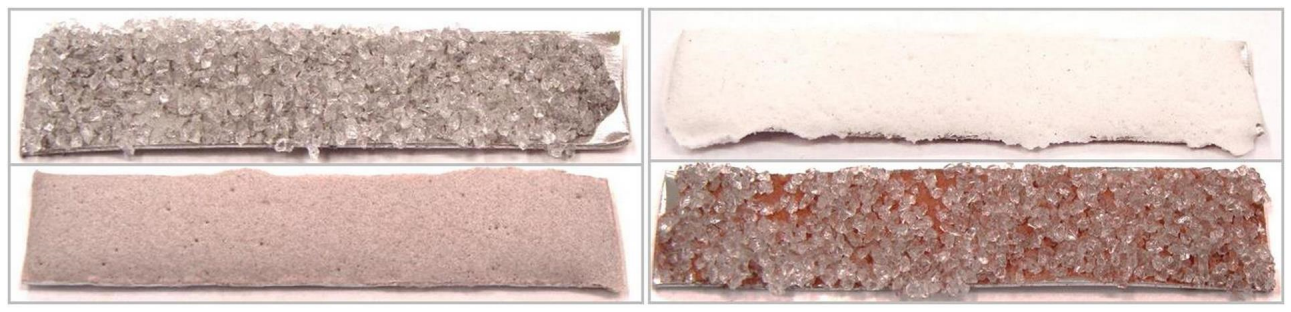

Fig. 5. The photographs of coated bed samples proposed by the authors.

\section{Summary}

The literature review and the author's research indicate, that there is a possibility to construct an adsorption bed which meets the requirements concerning mechanical strength and sorption capacity. Furthermore, the authors work on developing a combined bed which integrates the advantages of coated and granular bed. The major advantage of coated bed is a reduction of thermal resistance and an elimination of thermal contact resistance between the heat exchanger surface and the adsorbent layer. While using an appropriate grain size and providing the channels for the flow of working fluid vapor, a granular bed demonstrates higher intensity of adsorption and desorption process with regard to the same layer thickness. For that purpose the materials that could serve as a binder where selected and tested considering their physico-chemical properties. Several solutions in terms of proportion of substances and the preparation of an adsorption bed were developed. The selection of appropriate adsorbent fraction and a heat-exchanger type is crucial for this application. The selection can be therefore supported by the comparison of constructions which are applied or tested in other studies.

Acknowledgment: The work was supported by Faculty of Energy and Fuels (15.11.210.460).

\section{References}

1. IEA, The Future of Cooling: Opportunities for energy-efficient air conditioning (2018)

2. C.A. Balaras, G. Grossman, H.M. Henning, C.A. Infante Ferreira, Erich Podesser, L. Wang, E. Wiemken, Renew. Sust. Energ Rev. 11 299-314 (2007)

3. K. Wang, E.A. Vineyard, Ashrae J., September 2011, 14-24 (2011)

4. R. Z. Wang, L. Wang, J. Wu, Adsorption refrigeration technology: theory and application, pp.5-7 (John Wiley \& Sons Inc, New York, 2014)

5. A.R.M. Rezk, R.K. Al-Dadah, S. Mahmoud, A. Elsayed, Appl. Th. Eng. 53, 278-284 (2013)

6. G.E. Hulse, Refr. Eng., 17 (2), 41-54 (1929)

7. A. Li, K. Thu, A.B. Ismail, K.C. Ng, Appl. Th. Eng. 93, 668-677 (2016) 
8. F. Poyelle, J.-J. Guilleminot, F. Meunier, Ind. Eng. Chem. Res. 38, 298-309 (1999)

9. G. Restuccia, A. Freni, S. Vasta, Y. Aristov, Int. J. Refrig. 27, 284-293 (2004)

10. H. Niazmand, H. Talebian, M. Mahdavikhah, Int. J. Refrig. 35, 2261-2274 (2012)

11. H. Niazmand, I. Dabzadeh, Int. J. Refrig. 35, 581-593 (2012)

12. J.-Y. San, F.-K. Tsai, Appl. Th. Eng. 70 274-281 (2014)

13. A. Sharafian, C. McCague, M. Bahrami, Int. J. Refrig. 51, 135-143 (2015)

14. A. Li, K. Thu, A.B. Ismail, M.W. Shahzad, K.C. Ng, Appl. Th. Eng. 92, 149-157 (2016)

15. A. Çağlar, Appl. Th. Eng. 104, 386-393 (2016)

16. M. Szyc, W. Nowak, Chem. Process Eng. 35, 109-119 (2014)

17. M. Chorowski, P, Pyrka, Energy 92, 221-229 (2015)

18. K. Grabowska, J. Krzywańksi, M. Sosnowski, W. Nowak, M. Wesołowska, K. Sztekler, A. Widuch, Int. Conf. on Energy, Power and Env. Eng. (2017)

19. J. Krzywański, K. Grabowska, F. Herman, P. Pyrka, M. Sosnowski, T. Prauzner, W. Nowak, En. Conv. and Management 153, 313-322 (2017)

20. A.R.M. Rezk, R.K. Al-Dadah, Appl. En. 89, 142-149 (2012)

21. K.-S. Chang, M.-T. Chen, T.-W. Chung, Appl. Th. Eng. 25, 2330-2340 (2005)

22. T.S. Ge, Y.J. Dai, R.Z. Wang, Z.Z. Peng, Energy 35, 2893-2900 (2010)

23. C.J. Chen, R.Z. Wang, Z.Z. Xia, J.K. Kiplagat, Z.S. Lu, Appl. En. 87, 2673-2681 (2010)

24. R. de Boer, S.F. Smeding, R.J.H. Grisel, Int. Sorption Heat Pump Conf. (2005)

25. W.-S. Chang, C.-C. Wang, C.-C. Shieh, Appl. Th. Eng. 27, 2195-2199 (2007)

26. A. Sapienza, S. Santamaria, A. Frazzica, A. Freni, Energy 36, 5532-5538 (2011)

27. A. Freni, L. Bonaccorsi, L. Celabrese, A. Capri A. Frazzica, A. Sapienza, Appl. Th. Eng. 82, 1-7 (2015)

28. Z. Rogala, P. Kolasiński, Z. Gnutek, Appl. Th. Eng. 127, 950-962 (2017)

29. S. Santamaria, A. Sapienza, A. Frazzica, A. Freni, I.S. Girnik, Y.I Aristov, Appl. Energy 134, 11-19 (2014)

30. Z. Rogala, Appl. Th. Eng. 121, 431-442 (2017)

31. S. Mitra, P. Kumar, K. Srinivasan, P. Dutta, Int. J. Refrig. 67, 174-189 (2016)

32. Y.L. Liu, R.Z. Wang, Z.Z. Xia, Appl. Th. Eng. 25, 359-375 (2005)

33. Y.L. Liu, R.Z. Wang, Z.Z. Xia, Int. J. Refrig. 28, 218-230 (2005)

34. R.H Mohammed, O. Mesalhy, M.L. Elsayed, L.C. Chow, Int. J. Refrig. 80, 238-251 (2017)

35. R.H Mohammed, O. Mesalhy, M.L. Elsayed, L.C. Chow, Appl. Th. Eng. 136, 293-300 (2018)

36. W.S. Chang, C.-C. Wang, C.-C. Shieh, Appl. Th. Eng. 29, 2100-2105 (2009)

37. A. Freni, F. Russo, S. Vasta, M. Tokarev, Y.I. Aristov, G. Restuccia, Appl. Th. Eng. 27, 2200-2204 (2007)

38. M. Verde, J.M. Corberan, R. de Boer, S. Smeding, Int. Sorption Heat Pump Conf. (2011) 